\title{
Vascular comorbidities in younger people with dementia: a cross-sectional population-based study of 616245 middle-aged people in Scotland
}

\author{
C A Heath, ${ }^{1}$ S W Mercer, ${ }^{2}$ B Guthrie ${ }^{3}$
}

- Additional material is

published online only. To view please visit the journal online (http://dx.doi.org/10.1136/ jnnp-2014-309033)

${ }^{1}$ Department of Neurology, Ninewells Hospital, Dundee, UK

${ }^{2}$ Department of Primary Care, University of Glasgow,

Glasgow, UK

${ }^{3}$ Department of Primary Care Medicine, University of Dundee, Dundee, UK

Correspondence to Dr Craig A Heath, Ninewells Hospital, Dundee, DD1 9SY, UK; craigheath@nhs.net

Received 22 July 2014 Revised 23 September 2014 Accepted 15 October 2014 Published Online First 18 November 2014

\section{CrossMark}

\section{To cite: Heath $C A$}

Mercer SW, Guthrie B. J

Neurol Neurosurg Psychiatry 2015:86:959-964.

\section{ABSTRACT}

Introduction There is growing evidence of an aetiological relationship between vascular risk factors and the development of dementia in later life. Dementia in the under-65s has historically been considered to be more driven by genetic factors, but previous epidemiological studies in the young have been relatively small. This study aims to determine the prevalence of vascular comorbidity in people aged $<65$ with dementia in comparison to the general population.

Methods Analysis of routine clinical data from 314 (30\%) general medical practices in Scotland.

Results From an overall population of 616245 individuals, 1061 cases of 'all-cause' dementia were identified (prevalence 172/100 000 population, 95\% Cl 161 to 182). The prevalence of dementia was higher in people with vascular morbidities, and prevalence progressively increased from 129/100 000 in people with no vascular comorbidity to $999 / 100000$ in people with four or more $(p=0.01)$. The strength of association was greatest with a previous transient ischaemic attack (TIA) or stroke and chronic kidney disease (adjusted $\mathrm{OR}=3.1$ and 2.9, respectively). Statistically significant, but smaller associations were seen with the presence of hypertension, diabetes, ischaemic heart disease and peripheral vascular disease (adjusted $\mathrm{OR}=1.4,2.0$, 1.9 and 2.2, respectively).

Discussions Vascular comorbid diseases were more commonly recorded in people aged 40-64 with dementia than those without. This finding indicates that vascular disease may be more important in the aetiology of young-onset dementia than previously believed, and is of concern given the continuing rise in obesity and diabetes internationally.

\section{INTRODUCTION}

Dementia is a growing global problem with an estimated 25 million cases worldwide in 2005. The costs of dementia to both individuals and society as a whole are large, with healthcare-related cost alone in the USA estimated at $\$ 200$ billion per year. ${ }^{1}$ There is growing evidence to support a role for both genetic and acquired risk factors for the development of dementia in the elderly. ${ }^{2}$ Consistent modifiable risk factors for the development of Alzheimer's and 'all-cause' dementia in older people are those associated with vascular disease and include diabetes, hypertension and obesity. ${ }^{3-8}$ Less robust evidence supports an association with smoking, chronic renal failure and psychological stressors including depression. ${ }^{9-11}$
Although, the prevalence of dementia rises exponentially with age, it is well recognised in younger people (usually arbitrarily defined as less than 65 years old). The importance of genetic factors in dementia of young onset has commonly been reported in the literature, but in clinical practice, inherited dementia is relatively uncommon. A positive family history of autosomal dominant dementia is seen in the minority of patients, even among those attending national centres of excellence (personal communication Professor Martin Rossor, National Hospital for Neurology and Neurosurgery, London, UK), but the role of potentially modifiable risk factors like vascular disease is unclear in this population. There have been a limited number of epidemiological studies of young onset dementia. With few exceptions, ${ }^{12}$ the primary aim has been to estimate the prevalence and cause of dementia, albeit often using data from selective populations, for example, those attending hospital clinics. The reported prevalence of dementia in the young varies from 38 to 420 per 100000 population, reflecting heterogeneity in study design and study population. $^{12-15}$ Alzheimer's disease remains the most common cause of dementia in younger people, but dementia associated with movement disorders or other neurodegenerative disorders are more commonly seen than in an older population. The relatively small numbers included in previous research in the young have rarely permitted an accurate assessment of potential risk factors; thus, the relative importance of modifiable risk factors in young onset dementia remains unclear.

The aim of this study is to determine the prevalence of young onset dementia in a large population sample, and the prevalence of vascular comorbid conditions in people with young onset dementia in comparison to the general population.

\section{METHODS}

The UK National Health Service (NHS) requires registration with a general medical practice to access healthcare services. UK general practitioners (GPs) universally use electronic medical records that include data on demography, the conditions an individual has and prescribing. Patients with dementia were identified from a data set of 1751841 people registered with 314 general practices in Scotland, covering approximately one-third of the Scottish population. The data set used for the analysis and definitions of the morbidities defined have been fully reported elsewhere, ${ }^{16}$ but 
in brief, at the time of data extraction, participating practices systematically used electronic medical records for registration of patients, morbidity recording (including dementia) and prescriptions. The data for this analysis are from all patients who were alive and permanently registered with a participating practice on 31 March 2007. The data set is representative of all Scottish patients in terms of age, sex and socioeconomic status. Dementia is one of the conditions included in the UK Quality and Outcomes Framework, under which GPs are paid to maintain accurate registers for common chronic conditions, and for the delivery of specified care to people with those conditions. This ensures that diagnoses are reviewed annually, and accuracy of diagnosis is financially incentivised. Additional data extracted were for age, sex, socioeconomic status defined by the Carstairs Score of the postcode of residence grouped into equal fifths of the population, and the presence of specified vascular and neurodegenerative comorbidities.

The NHS National Research Ethics Service had previously approved the anonymous use of these data for research purposes; therefore, this study did not need individual ethics approval.

\section{Case definition}

Dementia was defined as the presence ever of one of a specified set of Read Codes (the standard morbidity coding used by NHS general practices) or the prescription ever of an anticholinesterase inhibitor (detailed in see online supplementary appendix 1). People with dementia were included if they were between 40 and 64 years old (inclusive) on 31 March 2007. The comparison population consisted of people between ages 40-64 with no record of dementia in the primary care record.

Prior to conducting the study, the accuracy of GP coding of young onset dementia was examined in a set of eight practices with a registered population of 51 147, where electronic records were screened to identify cases of young onset dementia using the same criteria as above, and the full primary care record including free-text and hospital letters reviewed. In total, 17350 people were aged between 40 and 64 years old, and 15 of them were coded as having dementia (estimated prevalence of $86.5 / 100000$ population $(95 \%$ CI 50.8 to 122.2$)$. On review, all diagnoses fulfilled Diagnostic and Statistical Manual of Mental Disorders (DSM) IV criteria for gradual onset and progressive impairment in memory function and at least one other cognitive domain resulting in impairment of social and occupational function.

\section{Statistical analysis}

The crude, age and gender-stratified prevalence of dementia was estimated with 95\% CIs calculated using Wilson's method with continuity correction. The proportion of people with and without dementia who had a vascular comorbidity (hypertension, ischaemic heart disease (IHD), diabetes, peripheral vascular disease, stroke or transient ischaemic attack (TIA) or chronic kidney disease (CKD) stage 3 or worse) was calculated and the $\mathrm{OR}=$ estimated using logistic regression with and without adjustment for age, sex and socioeconomic status. A Breslow Day test for homogeneity of OR was undertaken to analyse the potential effect modification of gender.

As a sense check to examine if known associations with dementia were found, the analysis was repeated for the presence of neurodegenerative disorders known to be associated with dementia (Parkinson's disease, multiple sclerosis and learning disability).
A Mantel-Haenszel linear-by-linear association test was used to test for linear association. All analyses were carried out in IBM SPSS V.11.

\section{RESULTS}

\section{Basic demographics}

In total, 616245 individuals aged between 40 and 64 inclusive were identified from a total population of 1751841 , of whom 1061 had a dementia diagnosis. People with dementia had a mean age of 55.6 years $(\mathrm{SD} \pm 6.9)$ and $657(62 \%)$ were women. Those without dementia were significantly younger (mean age $=51.2 \mathrm{SD} \pm 7.2) \mathrm{p}<0.01)$ and $49.5 \%$ were women .

\section{Prevalence rates}

The overall prevalence of dementia in those between the ages of 40 and 64 was 172 (95\% CI 161 to 172) per 100000 population (table 1). Prevalence increased with age from 75/100 000 population in those aged 40-44, to 399/100 000 identified between the ages 60 and 64. Prevalence of dementia was inversely related to socioeconomic status with lowest prevalence noted in the most affluent. The overall prevalence in the most affluent fifth of the population was 119 (95\% CI 99 to 139) per 100000 in comparison to 226 (95\% CI 196 to 256) per 100000 population in the least affluent fifth.

The prevalence of dementia was higher in people with vascular morbidities, and prevalence progressively increased with the number of vascular comorbidities, from 129/100 000 in people with no vascular comorbidity to $999 / 100000$ in people with four or more $(\mathrm{p}=0.01)$.

Vascular comorbidities were common in people with dementia, with 27\% having hypertension, 9\% IHD and 12\% diabetes (table 2). They were more common in people with dementia in comparison to the general population. As expected given that people with dementia were somewhat older than people without, age adjustment reduced the crude associations seen, but people with dementia were more likely to have all of the vascular comorbidities examined, the strongest associations being with stroke/TIA and CKD (adjusted OR=3.1, 95\% CI 2.4 to $4.0 ; 2.9,95 \%$ CI 2.1 to 4.0 , respectively). Associations were weaker but still statistically significant for other vascular comorbidities, with adjusted ORs of 2.0 or more for diabetes and peripheral vascular disease, and somewhat weaker associations with IHD and hypertension. In total, 59\% of people with dementia had no vascular comorbidity, compared with $79.4 \%$ of people without dementia (adjusted $\mathrm{OR}=0.6,95 \% \mathrm{CI} 0.5$ to 0.7 ), and people with dementia were much more likely to have multiple vascular comorbidities. Analysis for linear trend (linear-by-linear association $=384,1 \mathrm{df}, \mathrm{p}<0.001$ ) demonstrates association between the number of vascular comorbid conditions and dementia with the greatest association identified in those with four or more comorbidities (table 3).

\section{Neurodegenerative and congenital disorders}

As expected, people with dementia were much more likely to have Parkinson's disease and learning disability compared with people without (adjusted OR=8.7, 95\% CI 4.4 to 16.9 and 7.1, 95\% CI 4.8 to 10.4 , respectively) with a weaker association with multiple sclerosis which was not significant after adjustment (adjusted $\mathrm{OR}=1.8$, 95\% CI 0.9 to 3.4 ), although the numbers are small for all these conditions (table 4).

\section{DISCUSSION}

To the best of our knowledge, this population-based study is the largest prevalence study of young onset dementia to date, and 


\section{Cognitive neurology}

Table 1 Prevalence of dementia (per 100000 population) in people aged 40-64 years by demographics and vascular morbidity

\begin{tabular}{|c|c|c|c|}
\hline & Number of individuals & Number of cases & $\begin{array}{l}\text { Prevalence of dementia per } \\
100000 \text { population }(95 \% \mathrm{Cl})\end{array}$ \\
\hline All people aged 40-64 & 616245 & 1061 & 172 (161 to 182$)$ \\
\hline \multicolumn{4}{|l|}{ Age group } \\
\hline 40-44 & 143010 & 108 & 75 (61 to 90 ) \\
\hline $45-49$ & 134880 & 127 & 94 (77 to 110$)$ \\
\hline $50-54$ & 118914 & 162 & 136 (115 to 157$)$ \\
\hline $55-59$ & 113029 & 240 & 212 (186 to 240$)$ \\
\hline $60-64$ & 106304 & 424 & 399 (360 to 436$)$ \\
\hline \multicolumn{4}{|l|}{ Gender } \\
\hline Male & 310999 & 404 & 130 (117 to 142$)$ \\
\hline Female & 305246 & 657 & 215 (198 to 231 \\
\hline \multicolumn{4}{|l|}{ Socioeconomic status } \\
\hline Quintile 1 (affluent) & 123663 & 147 & 119 (99 to 139$)$ \\
\hline Quintile 2 & 136549 & 175 & 128 (108 to 148$)$ \\
\hline Quintile 3 & 139662 & 278 & 199 (179 to 219$)$ \\
\hline Quintile 4 & 114056 & 230 & 202 (182 to 222 ) \\
\hline Quintile 5 (deprived) & 102123 & 231 & 226 (196 to 256$)$ \\
\hline \multicolumn{4}{|l|}{ Vascular comorbidity } \\
\hline Stroke/TIA & 8405 & 67 & 797 (607 to 987$)$ \\
\hline Chronic kidney disease & 4850 & 40 & 825 (570 to 1079$)$ \\
\hline Ischaemic heart disease & 21513 & 99 & $460(370$ to 550$)$ \\
\hline Diabetes & 30620 & 129 & 421 (348 to 493 ) \\
\hline Hypertension & 92542 & 287 & $310(274$ to 346$))$ \\
\hline Peripheral vascular disease & 7056 & 38 & 539 (367 to 709 ) \\
\hline \multicolumn{4}{|l|}{ Number of vascular comorbidities } \\
\hline None & 488251 & 630 & 129 (118 to 139$)$ \\
\hline One & 96994 & 257 & 265 (232 to 297$)$ \\
\hline Two & 24262 & 131 & 540 (447 to 632$)$ \\
\hline Three & 5107 & 33 & 725 (491 to 957 ) \\
\hline Four or more & 1001 & 10 & 999 (382 to 1615$)$ \\
\hline
\end{tabular}

Table 2 Prevalence of vascular morbidities in middle-aged people with and without dementia

\begin{tabular}{|c|c|c|c|c|c|}
\hline Vascular comorbidity present & $\begin{array}{l}\text { Number of individuals } \\
\text { without dementia }\end{array}$ & $\begin{array}{l}\text { Number of individuals } \\
\text { with dementia }\end{array}$ & $\begin{array}{l}\text { Crude OR } \\
(95 \% \mathrm{Cl})\end{array}$ & $\begin{array}{l}\text { *Adjusted OR } \\
(95 \% \mathrm{Cl})\end{array}$ & $\begin{array}{l}\text { tAdjusted OR } \\
(95 \% \mathrm{Cl})\end{array}$ \\
\hline \multicolumn{6}{|l|}{ Stroke/TIA } \\
\hline Yes & 8338 & 67 & 4.9 (3.8 to 6.3$)$ & 3.3 (2.6 to 4.2 ) & 3.1 (2.4 to 4.0$)$ \\
\hline No & 606846 & 994 & & & \\
\hline \multicolumn{6}{|l|}{ CKD } \\
\hline Yes & 4810 & 40 & 5.0 (3.6 to 6.8$)$ & $3.0(2.1$ to 4.1$)$ & 2.9 (2.1 to 4.0$)$ \\
\hline No & 610374 & 1021 & & & \\
\hline \multicolumn{6}{|l|}{ IHD } \\
\hline Yes & 21414 & 99 & 2.9 (2.3 to 3.5$)$ & 1.9 (1.5 to 2.4$)$ & 1.9 (1.5 to 2.4$)$ \\
\hline No & 593770 & 962 & & & \\
\hline \multicolumn{6}{|l|}{ Diabetes } \\
\hline Yes & 30491 & 129 & 2.6 (3.2 to 4.5$)$ & 2.1 (1.7 to 2.5$)$ & 2.0 (1.7 to 2.5$)$ \\
\hline No & 584693 & 932 & & & \\
\hline \multicolumn{6}{|l|}{ Hypertension } \\
\hline Yes & 92255 & 287 & 2.1 (1.8 to 2.4$)$ & 1.4 (1.2 to 1.6$)$ & 1.4 (1.2 to 1.6$)$ \\
\hline No & 522929 & 774 & & & \\
\hline \multicolumn{6}{|l|}{ PVD } \\
\hline Yes & 7018 & 38 & 3.2 (2.3 to 4.5 ) & 2.3 (1.7 to 3.2 ) & $2.2(1.6$ to 3.1$)$ \\
\hline No & 608166 & 1023 & & & \\
\hline
\end{tabular}

${ }^{*}$ Adjusted for age and gender.

†Adjusted for presence of age/gender/neurodegenerative disorder/learning disability/socioeconomic status.

CKD, chronic kidney disease; IHD, ischaemic heart disease; PVD, peripheral vascular disease. 
Table 3 Association between increasing number of vascular comorbid conditions and dementia

\begin{tabular}{llll}
\hline $\begin{array}{l}\text { No vascular } \\
\text { comorbidities }\end{array}$ & $\begin{array}{l}\text { Number of } \\
\text { individuals } \\
\text { without } \\
\text { dementia }\end{array}$ & $\begin{array}{l}\text { Number of } \\
\text { individuals with } \\
\text { dementia (\%) }\end{array}$ & $\begin{array}{l}\text { Adjusted* OR } \\
(95 \% \mathrm{Cl})\end{array}$ \\
\hline None & 488251 & $630(0.13)$ & 1 (reference) \\
One & 96994 & $257(0.26)$ & $1.5(1.3$ to 1.7$)$ \\
Two & 24262 & $131(0.54)$ & $2.8(2.3$ to 3.4$)$ \\
Three & 5107 & $33(0.73)$ & $3.1(2.2$ to 4.5$)$ \\
Four or more & 1001 & $10(1)$ & $4.6(2.5$ to 8.8$)$ \\
\hline
\end{tabular}

${ }^{*}$ Adjusted for presence of age/gender/neurodegenerative disorder/learning disability/ socioeconomic status.

additionally, it examines the presence of multiple vascular comorbidities in people with young onset dementia compared with the general population. The large cohort examined includes approximately one-third of the Scottish population, and the cohort is known to be representative of the total population in terms of age, sex and socioeconomic status. ${ }^{16}$ The overall reported prevalence was $172 / 100000$ population and is close to the middle of the range of estimates in previous studies but more precisely estimated. ${ }^{12-15} 1718$ There is variability in prevalence estimates in the literature, which is likely due to heterogeneity in study design. In general terms, previous studies have taken two forms: population-based studies and registrybased studies. Population-based studies have tended to only include those at greatest risk, typically a narrower and older age range than this study and thus have reported higher prevalence rates. Ott et $a l^{14}$ only included people aged 55-65 years, and the reported overall prevalence of $420 / 100000$ is consistent with the estimated prevalence of 399/100 000 in this age group within the current study. Registry-based studies have more accurate case classification for those included, but are likely to have lower case ascertainment. This is illustrated in a study by Harvey et $a l^{13}$ which was undertaken in two inner city London Boroughs and provides the most accurate case classification to date. The reported prevalence rate of 54/100 000 (CI 45 to 64) in people aged $30-64$ and 78/100 000 in people aged 40-64 is considerably lower than the current study, but patients were identified by health and social care referral at a time when electronic coding of dementia in primary care records was incomplete, and thus likely to lead to underascertainment. Finally, the large population included within the current study allows prevalence to be estimated with reasonable precision, which is important when examining rare diseases, with the CIs around the estimated overall prevalence of $172 / 100000$ being relatively narrow (95\% CI 161 to 182 ).

This study shows a strong association between vascular disease and dementia in those aged between 40 and 64. The strength of association is greatest with a history of previous TIA/ stroke, but significant associations are also seen with CKD, hypertension, diabetes, IHD and peripheral vascular disease, and people with dementia were much more likely to have multiple comorbidities. Cerebrovascular disease has consistently been associated with an increased risk of dementia in older people with $10 \%$ of patients with stroke developing dementia. ${ }^{19}$ In addition, the presence of white matter changes on MRI of the brain, often termed 'small vessel disease', has been shown to increase subsequent risk of dementia in individuals without overt symptomatic strokes. ${ }^{20}$ The mechanism by which cerebrovascular disease confers an increased risk of dementia remains unclear; however, current opinion favours a complex interaction between frank symptomatic strokes, pre-existing leucoaraiosis and ongoing exposure to existing vascular risk factors, and similar processes are likely to be at play in younger people.

The association between glucose metabolism and dementia in the elderly has been investigated extensively with growing robust evidence for an association between impairment of glucose metabolism (including diabetes) and the development of cognitive decline. ${ }^{3-5}$

A number of observational studies have found a twofold increase risk of dementia in comparison to controls. The largest meta-analysis of people with type 2 diabetes demonstrates an overall relative risk of 1.5 and 2.48 for those with Alzheimer's and vascular dementia, respectively. ${ }^{21}$ People with diabetes appear to have greater rate of cognitive decline in comparison to controls prior to the development of dementia per se. ${ }^{22} 23$ Interestingly, people in an older cohort with diabetes and additional vascular risk factors were found to have a greater risk of dementia than those who only have diabetes. ${ }^{24}$ The mechanism underlying the association between diabetes and dementia is unclear. Long-term glycaemic control may be important but this has not been definitively shown, and large-scale longitudinal data will be required to examine this further.

Studies of the association between hypertension and the risk of developing dementia have not always provided consistent results, particularly when hypertension is identified in later life. ${ }^{25}$ Hypertension measured in middle age consistently seems to increase the risk cognitive impairment in the elderly. ${ }^{7}$ The current study provides supportive evidence of an association between hypertension and dementia in a younger cohort as

Table 4 Prevalence of neurodegenerative disorders and learning disability in middle-aged people with and without dementia

\begin{tabular}{|c|c|c|c|c|}
\hline Presence of comorbid condition & $\begin{array}{l}\text { Number of individuals } \\
\text { without dementia }\end{array}$ & $\begin{array}{l}\text { Number of individuals } \\
\text { with dementia }\end{array}$ & OR (95\% Cl) & *Adjusted OR (95\% Cl) \\
\hline \multicolumn{5}{|l|}{ Parkinson's disease } \\
\hline Yes & 389 & 9 & 13.5 (7 to 26.3 ) & 8.7 (4.4 to 16.9 ) \\
\hline No & 614795 & 1952 & & \\
\hline \multicolumn{5}{|l|}{ Learning disability } \\
\hline Yes & 2679 & 27 & 6.5 (4.4 to 9.5$)$ & 7.1 (4.8 to 10.4$)$ \\
\hline No & 612705 & 1034 & & \\
\hline \multicolumn{5}{|l|}{ Multiple sclerosis } \\
\hline Yes & 2525 & 9 & 2.1 (1.1 to 4.0$)$ & $1.8(0.9$ to 3.4$)$ \\
\hline No & 612659 & 1052 & & \\
\hline
\end{tabular}

\footnotetext{
${ }^{*}$ Adjusted for age/gender/socioeconomic status.
} 
well. The associations between dementia, peripheral vascular disease and CKD are less well established. A single Japanese study found a positive association between stage 3 CKD and the risk of dementia in an older cohort. ${ }^{10}$ In addition, recent results from the Edinburgh type 2 diabetes study suggest an increased risk of dementia in those with reduced Ankle-Brachial Pulse Index (APBI) in an older cohort. ${ }^{26}$ Although the exact aetiology remains unclear, it is likely that both disorders reflect widespread disease within the vasculature, including the small cerebral vessels, thus the association found in this study is not unexpected.

Like all cross-sectional studies, this analysis can only show association rather than directly examine causality. Nordström et $a l^{12}$ recently reported the findings of a large cohort study examining risk factors for the development of dementia in the young by following up men identified from the Swedish Military Service Conscription Register with baseline variables measured at army entry and follow-up data (median follow-up 37 years) obtained from the Swedish National Hospital Discharge Patient Register. The prevalence of dementia was reported as 92/100 000 population with a median age at follow-up of 54 years, but the study did not include women (who make up over $60 \%$ of people with dementia in the current study), those with pre-existing learning disability or movement disorder. A history of hypertension and stroke conferred an increased lifetime risk of dementia at follow-up, but angina in the absence of myocardial infarction, CKD and peripheral vascular disease were not examined. The risk of dementia was also greatest in those with excessive alcohol intake at baseline, although data on alcohol intake were incomplete. In the current study, recording of alcohol intake was incomplete or poorly quantified and not analysed.

The current study has the limitations common to all crosssectional studies and those using routine clinical data. Dementia may be misdiagnosed or under-recorded in this population, although referral to a specialist dementia service would be routine clinical practice in the UK, particularly in the young. In addition, accurate recording is financially incentivised and a case note review of patients identified using the same electronic data case definition suggests that coding is accurate. Nonetheless, it is possible that there is under-recording of dementia, although we believe this is less likely in younger people than the very old. ${ }^{27}$ If there is under-recording, then it is unlikely to alter the findings since young onset dementia is rare, so misclassifying a proportion of true cases as not having dementia will not meaningfully change the control group characteristics. Additionally, it is important to recognise that cross-sectional analyses can examine association but cannot establish causality, and it is possible that the causal relationship is because people with dementia are better screened for vascular disease rather than because vascular disease is a cause of dementia in this population. However, there has been extensive improvement activity for many years to promote case finding for hypertension and diabetes with financial incentives to regularly measure blood pressure in all middle-aged people, and most of the other conditions are diagnosed after an individual develops symptoms making better screening of people newly diagnosed with dementia unlikely to explain the findings. Nonetheless, causality will be better established using longitudinal methods.

Historically, genetic factors have been considered to be the most important cause of dementia in the young. Genetic factors in dementia have been investigated extensively with the role of ApoE4 established. The presence of ApoE4 confers an increased risk of dementia and appears to influence age of onset. ${ }^{28-30}$
However, genetic testing including ApoE status is not routine clinical practice, precluding their examination in this study.

This study provides evidence to support an association between vascular risk factors, or evidence of existing vascular disease, and the risk of dementia in those between the ages of 40-64. These findings are likely to have significant implications for developed and developing countries given the exponential rise in obesity and diabetes. The relative importance of acquired risk factors in comparison to genetic predisposition remains unclear. The most plausible explanation is that the age of onset and overall risk of dementia is likely to reflect a complex interaction between both genetic and acquired risk factors.

The association between vascular disease and the risk of dementia in the young provides an opportunity for potential intervention and, perhaps, prevention. It is possible that people at higher risk of dementia would benefit from more aggressive vascular risk factor reduction than the general population, but establishing this definitively would require large clinical trials with very long follow-up, and analysis using observational data is more feasible (although also more prone to confounding). Large population-based longitudinal studies with careful ascertainment of dementia type are needed to examine the relative importance of acquired and genetic risk factors, improve diagnosis and allow prediction of prognosis in younger people with dementia.

Contributors Each author has made a substantial contribution to the design, acquisition and analysis of data. A final draft of the paper was agreed on prior to submission.

Funding CAH was supported by National Health Service Career Research Fellowship scheme, and data set creation was supported by Scottish Government Chief Scientist Office Applied Research Programme Grant 07/01.

Competing interests None.

Ethics approval The NHS National Research Ethics Service had previously approved the anonymous use of these data for research purposes.

Provenance and peer review Not commissioned; externally peer reviewed.

\section{REFERENCES}

1 Alzheimer's Association. 2010 Alzheimer's disease facts and figures. Alzheimers Dement 2010;6:158-94.

2 Reitz C, Brayne C, Mayeux R. Epidemiology of Alzheimer's disease. Nat Rev Neurol 2011;7:137-52.

3 Ott A, Stolk RP, van Harskamp F, et al. Diabetes mellitus and the risk of dementia: The Rotterdam Study. Neurology 1999;53:1937-42.

4 Leibson CL, Rocca WA, Hanson VA, et al. The risk of dementia among persons with diabetes mellitus: a population-based cohort study. Ann N Y Acad Sci 1997:826:422-7.

5 Luchsinger JA, Tang MX, Stern Y, et al. Diabetes mellitus and risk of Alzheimer's disease and dementia with stroke in a multiethnic cohort. Am J Epidemiol 2001;154:635-41.

6 Knopman D, Boland LL, Mosley $T$, et al. Cardiovascular risk factors and cognitive decline in middle-aged adults. Neurology 2001;56:42-8.

7 Launer LJ, Masaki K, Petrovitch $\mathrm{H}$, et al. The association between midlife blood pressure levels and late-life cognitive function. The Honolulu-Asia Aging Study. JAMA 1995;274:1846-51.

8 Profenno LA, Porsteinsson AP, Faraone SV. Meta-analysis of Alzheimer's disease risk with obesity, diabetes, and related disorders. Biol Psychiatry 2010;67:505-12.

9 Ott A, Slooter AJ, Hoffman A, et al. Smoking and risk of dementia and Alzheimer's disease in a population-based cohort study: the Rotterdam Study. Lancet 1998;351:1840-3.

10 Sasaki Y, Marioni R, Kasai M, et al. Chronic kidney disease: a risk factor for dementia onset: a population-based study. The Osaki-Tajiri Project. J Am Geriatr Soc 2011;59:1175-81

11 Breno S, Diniz BS, Butters MA, et al. Late-life depression and risk of vascular dementia and Alzheimer's disease: systematic review and meta-analysis of community-based cohort studies. Br J Psychiatry 2013;202:329-35.

12 Nordström $P$, Nordström A, Eriksson M, et al. Risk factors in late adolescence for young-onset dementia in men: a nationwide cohort study. JAMA Intern Med 2013;173:1612-18. 


\section{Cognitive neurology}

13 Harvey RJ, Skelton-Robinson M, Rossor MN. The prevalence and causes of dementia in people under the age of 65 years. J Neurol Neurosurg Psychiatry 2003;74:1206-9.

14 Ott A, Breteler MM, van Harskamp F, et al. Prevalence of Alzheimer's disease and vascular dementia: association with education. The Rotterdam study. BMJ 1995;310:970-3.

15 Kokmen E, Beard CM, Offord KP, et al. Prevalence of medically diagnosed dementia in a defined United States population: Rochester, Minnesota, January 1, 1975. Neurology 1989;39:773-6.

16 Barnett K, Mercer SW, Norbury M, et al. Epidemiology of multimorbidity and implications for health care, research, and medical education: a cross-sectional study. Lancet 2012;380:37-43.

17 Ikejima C, Yasuno F, Mizukami K, et al. Prevalence and causes of early-onset dementia in Japan: a population-based study. Stroke 2009;40:2709-1.

18 Newens AJ, Forster DP, Kay DW, et al. Clinically diagnosed presenile dementia of the Alzheimer type in the Northern Health Region: ascertainment, prevalence, incidence and survival. Psychol Med 1993;23:631-44.

19 Pendlebury ST, Rothwell PM. Prevalence, incidence, and factors associated with pre-stroke and post-stroke dementia: a systematic review and meta-analysis. Lancet Neurol 2009;8:1006-18.

20 Inzitari D, Pracucci G, Poggesi A, et al. Changes in white matter as determinant of global functional decline in older independent outpatients: three year follow-up of LADIS (leukoaraiosis and disability) study cohort. BMJ 2009;6:339-57.

21 Cheng $G$, Huang $C$, Deng $H$, et al. Diabetes as a risk factor for dementia and mild cognitive impairment: a meta-analysis of longitudinal studies. Intern Med J 2012;42:484-91.
22 Kerti L, Witte A, Winkler A, et al. Higher glucose levels associated with lower memory and reduced hippocampal microstructure. Neurology 2013;13:25-9.

23 Rouch I, Roche F, Dauphinot V, et al. Diabetes, impaired fasting glucose, and cognitive decline in a population of elderly community residents. Aging Clin Exp Res 2012:24:377-83.

24 Xu WL, Qiu CX, Wahlin A, et al. Diabetes mellitus and risk of dementia in the Kungsholmen project: a 6 -year follow-up study. Neurology 2004;63:1181-6.

25 Launer LJ, Ross GW, Petrovitch $\mathrm{H}$, et al. Midlife blood pressure and dementia: the Honolulu-Asia Aging Study. Neurobiol Aging 2000;21:49-55.

26 Feinkohl I, Keller M, Robertson CM, et al. Clinical and subclinical macrovascular disease as predictors of cognitive decline in older patients with type 2 diabetes: the Edinburgh type 2 diabetes study. Diabetes Care 2013;36:2779-86.

27 Alzheimer's Society, Alzheimer Scotland, Action on Dementia. Mapping the Dementia Gap 2011: progress on improving diagnosis of dementia 2010-2011. 2012.

28 Poirier J, Davignon J, Bouthillier D, et al. Apolipoprotein E polymorphism and Alzheimer's disease. Lancet 1993;342:697-9.

29 Corder EH, Saunders AM, Strittmatter WJ, et al. Gene dose of apolipoprotein E type 4 allele and the risk of Alzheimer's disease in late onset families. Science 1993;261:921-3.

30 Kurz A, Corder EH, Saunders AM, et al. Apolipoprotein E type 4 allele and Alzheimer's disease: effect on age at onset and relative risk in different age groups. J Neurol 1996;243:452-6. 